\title{
EL MITO PARADIGMÁTICO. LA FIESTA PUNITIVA Y EL ARTE DE HACER SUFRIR
}

\section{MARÍA CECILIA COLOMBANI ${ }^{1}$}

Resumen: El proyecto del presente trabajo consiste en efectuar una lectura del mito de Prometeo en el marco de las consideraciones vertidas por F. Nietzsche y M. Foucault en relación a la ejemplaridad de los castigos a partir de las características de las faltas cometidas; la transgresión que la misma ha producido es de tal envergadura que amerita un tipo de castigo inscrito en el escenario de la fiesta punitiva. Se trata de rastrear una cierta prehistoria del arte de hacer sufrir. El trabajo está articulado en tres momentos. Un largo apartado referido al Mito de Prometeo. Un segundo momento donde se analiza la escena del castigo impartido por Zeus a Prometeo. Un tercer momento donde se analiza la economía del castigo que Zeus inaugura como modo de reafirmar su soberanía, convirtiendo al cuerpo supliciado en cuerpo político, a partir del entrecruzamiento con las consideraciones de M. Foucault en torno a la relación cuerpo- castigo.

Palabras clave: Mito, Castigo, Prometeo, Nietzsche, Foucault.

\section{INTRODUCCIÓN}

El proyecto del presente trabajo consiste en efectuar una lectura del mito de Prometeo en el

\footnotetext{
${ }^{1}$ Professora da Facultad de Filosofía, Ciencias de la Educación y Humanidades (Universidad de Morón) e da Facultad de Humanidades (Universidad Nacional de Mar del Plata). E-mail: ceciliacolombani@hotmail.com.
}

marco de las consideraciones vertidas por F. Nietzsche y M. Foucault en relación a la ejemplaridad de los castigos a partir de las características de las faltas cometidas; la transgresión que la misma ha producido es de tal envergadura que amerita un tipo de castigo inscrito en el escenario de la fiesta punitiva.

Se trata de rastrear una cierta prehistoria del arte de hacer sufrir. Podemos pensar en encuadre del trabajo desde la propuesta arqueológica del propio Foucault y entonces pensar en el mito como una primera capa o pliegue de esa tecnología política de hacer sufrir como modo de reparar una falta que ha jaqueado una normatividad o legalidad imperante ${ }^{2}$.

Desandar la huella de la historia de los castigo nos lleva al mito hesiódico como relato emblemático de la soberanía ${ }^{3}$. En efecto, la figura de Zeus

\footnotetext{
${ }^{2}$ En la Arqueología del saber Michel Foucault sostiene que toda configuración epocal articula una cierta manera de ver y nombrar el mundo. La trabazón entre lo se ve y los nombres con que se nombra aquello que se ve constituye una forma de saber histórico y por ende deviniente y siempre en perspectiva. Un saber es así una forma de ordenar aquello que sobre la superficie aparece para ser conocido y para ser nombrado.

${ }^{3}$ El presente trabajo toma el cuerpo dedicado al mito de Prometeo de mi tesis doctoral "Una aproximación arqueológica al discurso hesiódico desde la lógica del linaje" de inminente edición por la editorial Universidad Nacional de Mar del Plata (EUDEM)
} 
garante, sostenida triunfalmente por Teogonía, supone la dureza y la crueldad del castigo para aquellos que han osado subvertir el orden real. Prometeo, el Japetónida, ha cometido ese tipo de falta que orada los cimientos mismos de lo real; por ello el castigo debe ser ejemplar, aleccionador y tomar la forma de un espectáculo continuado para que la lección paradigmática sea internalizada.

El trabajo está articulado en tres momentos. Un largo apartado referido al Mito de Prometeo, minuciosamente analizado y con aportes que van, incluso, más allá del objeto de análisis del presente artículo.

Un segundo momento donde se analiza la escena del castigo impartido por Zeus a Prometeo, específicamente, la escena donde un águila devora el hígado del Japetónida. El episodio se pondrá en relación con las consideraciones de F. Nietzsche en torno a la relación memoria-castigo, a partir de un análisis crítico de la Genealogía de la moral.

Un tercer momento donde se analiza la economía del castigo que Zeus inaugura como modo de reafirmar su soberanía, convirtiendo al cuerpo supliciado en cuerpo político, a partir del entrecruzamiento con las consideraciones de M. Foucault en torno a la relación cuerpo- castigo

\section{LA LECCIÓN MÍTICA}

El mito de Prometeo y Pandora, que tanto Teogonía como Trabajos y días devuelven constituye el mito fundacional que da cuenta de esta heterogeneidad de planos, esta dualidad entre lo divino y lo humano. Este último está atravesado por la ambigüedad que caracteriza la edad de hierro. La primera forma de ambigüedad la origina Prometeo al creer que engaña a Zeus en el reparto del primer sacrificio. En efecto, el mito narra la astucia de Prometeo y el consecuente castigo por parte de Zeus, de desconocer el límite entre hombres y dioses.

El objetivo primario de la historia es explicar el destino de Prometeo frente al castigo que Zeus le impone por sus faltas. El segundo objetivo es explicar el origen del mal entre los hombres. Lo que Prometeo paga es la culpa por la insensata sabidu- ría, por la hýbris de haber desafiado a Zeus, menoscabando su inteligencia con un pretendido engaño. Los pecados de Prometeo son dos: presumir de su sabiduría al creer que engaña a Zeus y robar el fuego al padre de hombres y dioses. Prometeo se las ingenia para robar el fuego, negado por Zeus a los hombres y sustituir el fuego natural por otro artificial. Esto supone, a su vez, transgredir la voluntad divina, lo que vuelve a reactualizar el tema de la hýbris, como exceso y desmesura. Dos son los castigos que impone el padre de hombres y dioses a tamaña desmesura: por un lado, Zeus niega a los hombres el fuego ante la primera falta y, en segundo lugar, la creación de Pandora, símbolo de los males del mundo. En el primer caso, Prometeo cree engañar a Zeus cuando, movido por su astucia, le da a elegir entre dos porciones, dos bocados diferentes, ambos cubiertos de piel, pero sólo uno conteniendo en su interior carne, mientras el otro, sólo guarda huesos y grasa. Zeus elige este último con lo cual queda fundado que el alimento humano será la carne. El mito de Prometeo funda así el rito sacrificial. En este momento hombres y dioses se separan, los hombres no tienen ya una comensalidad directa con los dioses y se inaugura la dependencia de los hombres frente a la carne cocida como alimento humano. La fundación del ritual rompe la vieja comensalidad entre hombres y dioses e inaugura esos tópoi que marcan la dimensión humana y la divina como razas o mundos impermeables. El sacrificio separa doblemente a los hombres: por un lado, de los dioses y por el otro, de los animales, ya que los hombres deben cocer la carne y cultivar el campo, mientras los animales comen crudo. Tal como lo muestra Detienne en Los Jardines de Adonis (1996, p. 112) en el reparto del primer sacrificio, los hombres se llevan la parte vinculada a lo corruptible, mientras que los dioses se llevan los aromas puros imputrescibles. La existencia humana queda definida por una posición intermedia, ambigua, entre lo crudo y lo quemado, lo podrido y lo imputrescible, lo bestial y lo divino. Se establece una relación vertical entre ambos, al tiempo que se instituye una relación horizontal entre los hombres. El sacrificio abre los dos planos porque obliga a los hombres a comer cierto tipo de alimento, mientras otros 
bocados corresponden a los dioses. El mito da origen a las prácticas sacrificiales, que es precisamente el modo en que los mortales se conectan con lo divino. El sacrificio es la forma en que los hombres donan algo a los dioses, desde su precaria condición antropológica. Asimismo, el mito abre un escenario específicamente antropológico: los hombres quedan condenados a cocinar los alimentos, quedando lo crudo reservado a los animales o bárbaros. A su vez, el mito inaugura las direccionalidades propias de la vida griega: por un lado, un eje vertical, que va de dioses a hombres, con la heterogeneidad que los caracteriza y, por otro, un eje horizontal, que va de hombre a hombre. Dos ejes, dos coordenadas, dos direccionalidades que definen ambos tópoi: lo sagrado y lo profano.

No es casual que sea Teogonía la que instituye este plano vertical que comunica hombres y dioses. Se trata del plan global de la obra: trazar linajes, líneas ascendentes y descendentes. Dice Hesíodo: "Prometeo presentó un enorme buey que había dividido con ánimo resuelto, pensando en engañar la inteligencia de Zeus. Puso, de un lado, en la piel, la carne y ricas vísceras con la grasa, ocultándolas en el vientre del buey. De otro, recogiendo los blancos huesos del buey con falaz astucia, los disimuló cubriéndolos de brillante grasa" (HESÍODO, Teogonía, v. 536-541).

Es esta astucia la que Zeus castiga, más allá de elegir voluntariamente su parte, sin desconocer el engaño, sabiendo también, de antemano, la condena que esto representaría para los hombres: cocinar para comer. Dice Detienne (1996, p. 112): "al proceder a este reparto desigual, Prometeo reconoció que la especie humana tenía una vital necesidad de comer carne. Y así, en realidad, llevó a cabo la voluntad de Zeus, que condenaba a los hombres a sufrir y a conocer la muerte". Fundamentalmente, Zeus no presta atención al engaño porque tiene preparado un castigo: no darles a los hombres el fuego, retornándolos a un estado de precariedad antropológica, ya que el mismo es un símbolo de la civilización. Nuevamente Prometeo transgrede la voluntad divina y roba el fuego. Es entonces el momento de Pandora. El castigo tiene cara de mujer. Sin embargo, aquí sólo importa la dimensión religiosa que define al eje vertical, y la justicia y castigo divinos ante las faltas de los hombres. El mito deja en claro que Zeus gobierna y castiga soberanamente.

La creación divina representa el definitivo castigo para los mortales: la mujer y la obligación de reproducirse a través de ella, ya que la necesidad de aparearse es el símbolo de la precariedad del hombre que necesita a la mujer para tener hijos. Es el inicio de la reproducción sexuada y con ello la fundación de un nuevo rasgo antropológico: el matrimonio como condición humana. Cocción de los alimentos y matrimonio pasan a ser los enclaves fundacionales de la condición humana. Pandora es esa primera mujer, madre de la raza de las mujeres, y cuna de la ruina para los hombres. Como dice Fontenrose (1974, p. 2), "the Pandora myth demand that we look upon Pandora as ancestress of living men and as archetype of womankind". Pandora como castigo implica, así, dos cosas: en primer lugar la necesidad de unirse sexualmente para la reproducción (el hombre ya no nacerá de la tierra, como ocurría en las otras razas) y, en segundo lugar, la mujer es un castigo porque desgasta al hombre. Pandora misma es un engaño, "la Apaté [Engaño] bajo la máscara de Filótes [Seducción]" (VERNANT, 2001, p. 61). Pandora también condena al hombre a una ambigüedad, ya que la necesita para reproducirse, pero, al mismo tiempo, lo desgasta y consume. Su figura es relevante en Trabajos y días, más que en Teogonía. Esto se debe a que, en el primer caso, Hesíodo quiere resaltar el origen del mal entre los hombres, mientras en el segundo caso la problemática dominante es el enfrentamiento de Prometeo y Zeus, escrito en clave de soberbia. Teogonía resalta el castigo, la separación vertical entre dioses y hombres. Por el contrario, Trabajos y días puntualiza el eje horizontal. Una obra que se sitúa en el plano humano y en su problemática, la tensión Díke y Hýbris, debe abrir la dimensión horizontal del mito. Al afirmar la separación entre dioses y hombres, Teogonía expone la distinta calidad de ser entre unos y otros, y, por eso, Hesíodo dice allí que Zeus "no dio la infatigable llama del fuego" (HESÍODO, Teogonía, v. 563). Pero en Trabajos y días el problema es el de los hombres y el del mito de las edades que sigue

Hélade - Volume 1, Número 2 (Dezembro de 2015) 
inmediatamente al mito de Prometeo. En esta obra, entonces, Hesíodo dice que Zeus "lo escondió". Esta diferencia se articula con la necesidad de explicar el paso de una edad a otra.

El mito de Prometeo y Pandora termina desarrollando lo que en Teogonía era sólo secundario: el matrimonio. Pandora introduce la ambigüedad en el hombre, ya que la mujer es necesaria para que el padre tenga una descendencia legítima. Cuando Hesíodo da los consejos a Perses para la administración familiar dice: "que no te haga perder la cabeza una mujer de trasero emperifollado, que susurre requiebros mientras busca tu granero. Quien se fía de una mujer, se fía de ladrones. Procura tener un solo hijo, para conservar intacto tu patrimonio; pues así la riqueza crecerá dentro de tu casa" (HESíODO, Trabajos y días, v. 373 y ss.). Por un lado, la mujer es símbolo de consumo, pérdida y desgaste, pero, por otro lado, es símbolo de fertilidad y reproducción.

Así queda definido el tópos propiamente humano como un espacio horizontal, donde los varones se vinculan con las mujeres para reproducirse. El matrimonio instituye las relaciones de alianza entre los distintos grupos de hombres. La relación filiativa del linaje es propia de Teogonía.

De este modo, la riqueza de la configuración mítica radica precisamente en la tensión que ambos tópoi juegan, sobre todo a partir de la distancia ontológica que los separa y los consecuentes movimientos de aproximación y asimilación, como modos de achicar la brecha ontológica.

El mito de Prometeo en Trabajos y días tiene por finalidad explicar la necesidad del trabajo en el horizonte de la justicia. Zeus rige el universo desde su ser justo y benévolo y en nombre de esos mismos caracteres que impone el trabajo como justa reparación al daño. Son estos temas que solidarizan, en un primer momento, maldad y trabajo, los que más tarde toman rumbos diferentes, ya que el trabajo se aleja de una perspectiva negativa, asociado al daño para convertirse en una dimensión positiva, vinculado a la realización humana. Es importante remarcarlo: el trabajo sólo en un primer momento resulta solidario de la noción de castigo; más tarde parece cobrar una realidad autónoma, por fuera de la sanción.
No obstante, nos proponemos aquí retomar la relación entre Zeus y Prometeo a partir de la hýbris de este último y de la lección-castigo que desata el Egidífero, sobre todo en relación a la proporción del castigo impartido que parece ser directamente proporcional a la necesidad de restaurar los tópoi que el Japetónida parece transgredir. "En unas cuantas décadas, ha desaparecido el cuerpo supliciado, descuartizado, amputado, marcado simbólicamente en el rostro o en el hombro, expuesto vivo o muerto, ofrecido en espectáculo" (FOUCAULT, 1976, p. 16).

Prometeo mide su poder con Zeus y éste responde con la crueldad teatral que exige la restauración del orden soberano. Tal como sostiene Foucault: "El problema de la relación entre crimen y castigo no se planteaba en términos de medida, igualdad o desigualdad mensurable. Entre uno y otro había más bien una especie de justa, de imponerse a él. En consecuencia, había un desequilibrio en el corazón mismo del acto punitivo" (FOUCAULT, 1976, p. 84).

Es desde esta lógica desde la cual castiga Zeus a un Prometeo insolente que no supo ver la disimetría de fuerzas. El castigo final del Japetónida así parece indicarlo. Pensemos el final del mito en ambas obras, luego de los canónicos castigos que incluyen a Pandora como eje del mal. Leemos en Teogonía: "De esta manera no es posible engañar ni transgredir la voluntad de Zeus; pues ni siquiera el Japetónida, el remediador Prometeo logró liberarse de su terrible cólera, sino que por la fuerza, aunque era muy astuto, le aprisionó una enorme cadena" (HESÍODO, Teogonía, v. 613-617). Si optamos por Trabajos y días, el tormento no es menor y la relación "crimen-castigo" encuentra una vez más la brutal disimetría que venimos rastreando: "Mil diversas amarguras deambulan entre los hombres: repleta de males está la tierra y repleto el mar. Las enfermedades ya de día ya de noche van y vienen a su capricho entre los hombres acarreando penas a los mortales en silencio, puesto que el providente Zeus les negó el habla. Y así no es posible en ninguna parte escapar a la voluntad de Zeus" (HESíODO, Trabajos y días, v. 100-106). Se trata de dos relatos de castigo inscritos en distintos registros. El primero se juega enteramente sobre la figura del Japetónida 
y el segundo alcanza más explícitamente a la humanidad toda. Hay que entender el cambio de estatuto en los diferentes objetivos del poeta en una obra y otra.

Retornemos a Teogonía. Conocemos el final de Prometeo, quien es encadenado a una roca, mientras un águila le devora diariamente las vísceras. Fiesta punitiva, espectáculo cotidiano que recuerda el castigo ejemplar que recae sobre quien ha osado la transgresión del orden regio; en Trabajos y días, la humanidad misma con su precariedad ontológica es el símbolo mismo del castigo paradigmático.

Allí está la humanidad con su rostro oscuro y negativo para recordar cotidianamente cómo los hombres han pagado la insolencia del Japetónida.

\section{EL ARTE EXQUISITO DE HACER SUFRIR. ESPECTÁCULO Y CASTIGO}

“¿Cómo hacerle una memoria al animalhombre? ¿Cómo imprimir algo en ese entendimiento del instante, entendimiento en parte obtuso, en parte aturdido, en esta viviente capacidad de olvido, de tal manera que permanezca presente?" (NIETZSCHE, 1972, p. 69).

La cita que encabeza el presente apartado nos marca el rumbo. Cómo generar en el hombre una memoria, precisamente él que es un animal que olvida fácilmente. Este es el desvelo nietzscheano en la Genealogía de la moral donde desmonta algunas ficciones históricas valiéndose precisamente de la genealogía como modo de análisis e instalación.

Prometeo ha transgredido el tópos que le corresponde frente a la soberanía de Zeus Padre, conocedor de designios, y ello amerita una forma de castigo ejemplar que genere en los mortales esa memoria constante y fija de la que habla Nietzsche para que ningún mortal ose una gesta semejante.

Se abre entonces el espectáculo del castigo, el ceremonial de la pena; porque sólo el castigo que se compaña con una ritualización que apela a la percepción del cuerpo supliciado se inscribe en la memoria. En esta empresa de ficcionar una memoria, "tal vez no haya, en la entera prehistoria del hombre, nada más terrible y siniestro que su mnemotécnica. "Para que algo permanezca en la memoria se lo graba a fuego; sólo lo que no cesa de doler permanece en la memoria" (NIETZSCHE, 1972, p. 69). La imagen de Prometeo encadenado y el águila devorando perpetuamente sus vísceras es la imagen más rotunda de la relación castigo-cuerpo.

El cuerpo del que ha transgredido una norma ancestral es el teatro de operaciones de un castigo que hace memoria en el cuerpo. Tal como afirma Nietzsche, "Cuando el hombre consideró necesario hacerse una memoria, tal cosa no se realizó jamás sin sangre, martirios, sacrificios; los sacrificios y empeños más espantosos [...] las mutilaciones más repugnantes [...], las más crueles formas rituales de todos los cultos religiosos [...] -todo esto tiene su origen en aquel instinto que supo adivinar en el dolor el más poderoso medio auxiliar de mnemónica" (NIETZSCHE, 1972, p. 70).

Zeus, en su calidad de garante de la justicia y de los topoi que no deben ser transgredidos para que se conserve la armonía del kosmos, es quien dispone las marcas de esta memoria inscrita en el cuerpo de Prometeo. Entonces, el castigo como teatro es el brazo ejecutor de la memoria que los hombres deben incorporar para no cometer la falta de Prometeo.

Zeus ha sido ofendido y el castigo ejemplar es el rito que cierra el delito y el sufrimiento físico, el dolor del cuerpo mismo, representan los elementos constitutivos de la pena. Zeus ha sufrido una afrenta que lo ha herido en su calidad de Padre. Así, "Durante el más largo tiempo de la historia humana se impusieron penas no porque al malhechor se le hiciese responsable de su acción [...] -sino, más bien, a la manera como todavía ahora los padres castigan a sus hijos, por cólera de un perjuicio sufrido, el cual se desfoga sobre el causante" (NIETZSCHE, 1972 , p. 72). Se trata de una especie de relación paterno-filial, donde la soberanía del Padre ha sido menoscabada por una acción indisciplinada de uno de sus "hijos", estatutariamente inscrito en un rango menor

Entonces, el castigo se presenta como un verdadero arte de las sensaciones. El espectáculo del 
águila devorando el hígado de Prometeo y las propias cadenas del Japetónida son un verdadero festival visual; un incentivo para la vista. Se trata siempre del gran espectáculo de la fiesta física porque sólo así se recuerda y se hace presente la memoria del "no debes".

El aparato teatral del sufrimiento evoca la imagen nietzscheana de la relación entre el acreedor y el deudor. Prometeo se convierte, sin duda, en el gran deudor de un acreedor que se instala como el garante del orden. Prometeo paga con su sufrimiento la culpa de haber infringido la organización cósmica que Zeus tutela desde su ojo que todo lo ve. Coincidimos con la inquietud de Nietzsche cuando se interroga: "¿De dónde ha sacado su fuerza esta idea antiquísima, profundamente arraigada y tal vez ya imposible de extirpar, la idea de una equivalencia entre perjuicio y dolor? Yo ya he adivinado: de la relación contractual entre acreedor y deudor" (NIETZSCHE, 1972, p. 72). En efecto, creemos que Prometeo ha roto el contrato que supone el reconocimiento de los topoi que constituyen los dos planos de lo real y que permiten la consolidación de un orden ontológico: el plano de los mortales y el de los Inmortales. Es la fractura de ese "contrato ancestral" lo que convierte a Prometeo en un deudor y a Zeus en un acreedor máximo; figura directamente proporcional a su condición de garante máximo. Atentar contra él es atentar contra el orden instituido y semejante osadía determina la condición del deudor.

Es por ello, por la disimetría estatutaria entre el acreedor y el deudor que Zeus impone una pena: “Pero muy principalmente el acreedor podía irrogar al cuerpo del deudor todo tipo de afrentas y de torturas, por ejemplo cortar de él tanto como pareciese adecuado a la magnitud de la deuda" (NIETZSCHE, 1972, p. 73). Tal parece ser el destino de Prometeo.

A propósito de la disimetría estatutaria y de poder que acabamos de referir, podemos comprender que Zeus refunda su soberanía cada día, ante cada minuto en que la pena se cumple. Tal como sostiene Nietzsche para pensar otro aspecto pero cuyo eco resuena en el presente trabajo, "Por medio de la "pena" infligida al deudor, el acreedor participa de un derecho de señores" (NIETZSCHE, 1972, p. 74-75). El derecho de señores es el derecho de imponer el orden y de garantizarlo cada vez que se ve amenazado. Zeus es el Señor y, como tal, actúa en consecuencia.

Si el castigo es una compensación de deudas, hay sin duda un resto para quien produce el castigo. No sólo su nombre y su autoridad brillan en el cielo de la reparación, sino que, seguramente, se produce un plus, una ganancia, un placer extra de ver reivindicado su nombre: "Preguntemos una vez más: ¿en qué medida puede ser el sufrimiento una compensación de "deudas"? En la medida en que hacer-sufrir produce bienestar en sumo grado, en la medida en que el perjudicado cambiaba el daño [...] por un extraordinario contra-goce: el hacer sufrir" (NIETZSCHE, 1972, p. 75).

\section{LAS MARCAS POLÍTICAS SOBRE EL CUERPO}

"La reducción de estas mil muertes a la estricta ejecución capital define toda una nueva moral propia del acto de castigar" (FOUCAULT, 1976, p. 22)

La penalidad de lo corporal se une al fasto punitivo del cuerpo y la sangre y con ello queda fundada la soberanía. Por ello entendemos que el cuerpo supliciado opera como un tópos político. Coincidimos con Michel Foucault cuando sostiene: "Pero el cuerpo está también directamente inmerso en un campo político; las relaciones de poder operan sobre él una presa inmediata; lo cercan, lo marcan, lo someten a suplicio, lo fuerzan a unos trabajos, lo obligan a unas ceremonias, exigen de él unos signos" (FOUCAULT, 1976, p. 32). La cita es elocuente en relación al planteo político que venimos ensayando. Si se ha intentado dañar la legitimidad del soberano, el cuerpo se convierte en blanco de acción punitiva y de espectáculo festivo.

Zeus impone a Prometeo un verdadero suplicio. Pero qué es un suplicio sino una pena corporal, dolorosa, más o menos atroz ${ }^{4}$. El garante castigo y

${ }^{4}$ Encyclopédie, artículo "Supplice" citado por Foucault (1976, 
lo hace desde la lógica del señorío, una lógica ejemplar para demostrar quién es el más apto.

Resulta interesante la consideración foucaultiana en relación al suplicio porque creemos que el concepto puede trasladarse a esa imagen atroz del hígado devorado por el águila. Dice Foucault: "El suplicio es una técnica y no debe asimilarse a lo extremado de un furor sin ley. Una pena para ser un suplicio debe responder a tres criterios principales: en primer lugar, ha de producir cierta cantidad de sufrimiento que se puede ya que no medir con exactitud al menos apreciar, comparar y jerarquizar" (FOUCAULT, 1976, p. 39). En primer lugar coincidimos en la relación que el castigo-suplicio tiene con la ley. La ley allí está presente como un principio de inteligibilidad que separa la conducta prudente de aquella que merece precisamente el castigo. No se trata de una instancia a-nómica, sino, por el contrario, de la ley que Zeus en calidad de nomothétes aplica por el daño recibido. Sin esta ley ancestral no hay kósmos ni legalidad que se sostenga.

Es cierto también el criterio que impera en el suplicio: una cierta y vigorosa cantidad de sufrimiento que se pueda apreciar, comparar y jerarquizar de modo tal que quede claro la idea de la transgresión y las bondades de la sumisión al tópos divino. Esa es la dimensión didáctica del castigo y su función paradigmática.

Sin duda Zeus se muestra como un maestro en el arte de castigar. Se trata ni más ni menos que la cabal manifestación del poder que castiga. Lo que está apareciendo es todo un dispositivo tendiente a reubicar los planos de lo real so pena de que puedan ser subvertidos determinando el retorno formas ancestrales vinculadas con lo informe que kháos representa. Coincidimos con Foucault cuando advierte que "En los excesos de los suplicios, se manifiesta toda una economía del poder" (FOUCAULT, 1976, p. 40). Una economía de poder que asegura el no retorno a etapas donde el kósmos no gozaba de la soberanía regia que el Egidífero ostenta.

El castigo pone sobre la escena cuestiones corporales (tal como venimos analizando) pero también temporales. Hay un tiempo en el arte de castigar

p. 39). que, en el caso del suplicio, se manifiesta como un continuum en la forma de ejercicio del castigo: "La muerte suplicio es un arte de retener la vida en el dolor, subdividiéndola en "mil muertes" (FOUCAULT, 1976, p. 39). La cita es magnífica. En efecto, la presencia continuada del águila devorando las entrañas de Prometeo encadenado aplaza la muerte, la desplaza hacia un tiempo eterno, hacia una muerte en continuado que no se termina de cerrar.

Esto está directamente relacionado con la idea de la memoria que revisáramos en nuestro segmento nietzscheano. Las "mil muertes" constituyen el mejor antídoto contra el olvido de la falta. El olvido del propio Prometeo y de la totalidad de los mortales. Las "mil muertes" son el eterno monumento de una memoria inscrita en el cuerpo y en el tiempo; tiempo cíclico porque cada día el hígado es devorado y vuelve a crecer para seguir posibilitando esa economía del castigo que es siempre de carácter político.

La continuidad del castigo, su exhibición pública, las "mil muertes" que lo sostienen nos permite reconocer que "El suplicio descansa sobre todo en un arte cuantitativo del sufrimiento" (FOUCAULT, 1976, p. 40). Sufrimiento de Prometeo y virtual sufrimiento de los mortales si no aprenden la lección arquetípica. Ese es el efecto de la exhibición. Se trata de introyectar el castigo como forma de no olvidar nunca que aquello puede rozarnos en su más brutal materialidad. Todos somos Prometeo.

Una expresión de Foucault nos marca un nuevo rumbo de análisis: "El cuerpo supliciado se inscribe en primer lugar en el ceremonial judicial que debe exhibir, a la luz del día, la verdad del crimen" (FOUCAULT, 1976, p. 41). Hasta aquí la cita. No se trata exactamente de un ceremonial judicial al modo en que lo toma Foucault teniendo en cuenta la configuración epocal que analiza. Recordemos que estamos en presencia de una justicia divina que viene del más allá (GERNET, 1981, p. 16). Lo que sí rescatamos con fuerza y suscribimos como una idea potente es la "verdad del crimen" o de la transgresión en este caso. En efecto, el ceremonial al que asistimos, a partir de las imágenes atroces y de fuerte impacto sensible que el poeta nos devuelve, ubica la verdad de la transgresión en el corazón mismo del cuerpo supliciado. El cuerpo habla y dice precisamente la 
verdad de la falta cometida. El cuerpo habla y no cesa de hablar porque el suplicio no cesa de exhibirse como un espectáculo festivo. Cuerpo-verdad es entonces la nueva relación a considerar. Hay en el castigo un efecto de verdad duradero, que se hace público porque esta publicidad es el soporte material de la memoria: "Y el cuerpo del condenado es de nuevo la pieza esencial en el ceremonial del castigo público. Corresponde al culpable manifestar a la luz del día su condena y la verdad del crimen que ha cometido. Su cuerpo exhibido, paseado, expuesto, supliciado, debe ser como el soporte público de un procedimiento que había permanecido hasta entonces en la sombra; en él, sobre él, el acto de justicia debe llegar a ser legible por todos" (FOUCAULT, 1976, p. 48).

Castigo y alétheia, en la medida en que el suplicio de-vela, des-cubre, des-oculta un sentido: no se puede transgredir el tópos divino. El suplicio des cubre el cuerpo y lo exhibe mortificado, amputado, supliciado. En realidad se está develando un sentido que es lo que el mito ofrece como relato fundacional.

Prometeo debe dar cuenta de su insolencia; mostrar su verdad; declarar su falta y el cuerpo exhibido en suplicio es la mejor garantía de esa verdad. Tal como sostiene Foucault, es necesario "Hacer en primer lugar del culpable el pregonero de su propia condena. Se le encarga, en cierto modo, de proclamarla y de atestiguar así la verdad de lo que se le ha reprochado" (FOUCAULT, 1976, p. 49). La humanidad toda se convierte en el público de este espectáculo ancestral dramatizado para todos los hombres y para toda la vida: nadie, como sabemos, puede presumir de su hybris engañando a la autoridad máxima

\section{CONCLUSIONES}

"Ante la justicia del soberano, todas las voces deben callar" (FOUCAULT, 1976, p. 41)

En efecto, tal como reza la cita que inaugura el segmento, el soberano impone una justicia que opera como el principio de legitimidad entre lo aceptable y lo no aceptable. Ante tamaño gesto, el lógos enmudece y sólo la vista goza del privilegio que los dioses tienen de hacer sufrir como modo de reparar la falta cometida. El habla queda suspendida y son los ojos los más fieles testigos de la ceremonia punitiva.

El presente trabajo se ha movido en tres frentes. En un primer momento nos referimos al mito de Prometeo y lo hemos hecho decir de sí todo lo que hemos podido para comprender la sustancia misma del mito en lo referente a la radical distancia que separa a hombres y dioses. Hemos presentado el relato mítico y, a partir de allí, hemos buceado por los distintos atajos que su gramática permite.

En un segundo momento cruzamos el discurso hesiódico con dos autores íntimamente relacionados entre sí en el tópico que pusimos en consideración, esto es la relación entre el castigo y la necesidad de hacer en el hombre una memoria para que evite nuevamente la transgresión y la relación entre el castigo y el cuerpo bajo la forma del suplicio como forma de criar esa memoria.

Así vimos cómo "La lentitud del suplicio, sus peripecias, los gritos y sufrimientos del condenado desempeñan, al término del ritual judicial, el papel de una prueba última" (FOUCAULT, 1976, p. 51). En efecto se trata de la prueba de su falta y de la prueba de esa memoria ficcionada al cobijo del arte de hacer sufrir.

A lo largo del trabajo vimos que el verdadero peligro es la pérdida de legitimidad del soberano. Zeus ha sido engañado, más allá de que él eligiera deliberadamente la porción conociendo el dolo, y esto pone en jaque la organicidad del kósmos. Prometeo es directamente responsable de una doble ofensa: la que ha cometido contra el soberano y la que ha cometido contra Diké. En efecto, es la justicia cósmica la que pudo haberse visto afectada.

Por eso es necesario el castigo ejemplar: "Se cierra el círculo: del tormento a la ejecución, el cuerpo ha producido y reproducido la verdad del crimen. O más bien constituye el elemento que a través de todo un juego de rituales y de pruebas confiesa que el crimen ha ocurrido, profiere que lo 
ha cometido él mismo, muestra que lo lleva inscrito en sí y sobre sí, soporta la operación del castigo y manifiesta de la manera más patente sus efectos" (FOUCAULT, 1976, p. 52). Si bien la cita habla de un crimen, creemos que el espíritu de la letra se presta perfectamente al juego de intersección textual.

En definitiva, el trabajo ha dado cuenta de cómo se procede contra el transgresor. Prometeo, como los Titanes, como Tifón, representan, no sólo formas de lo Otro en tanto formas de subversión del orden, sino resueltos enemigos de un dispositivo político que funciona bajo la ley del soberano; por ello: "El derecho a castigar será, pues, como un aspecto del derecho a hacer la guerra a sus enemigos" (FOUCAULT, 1976, p. 53).

Memoria y castigo; cuerpo y castigo; memoria y suplicio; cuerpo como tópos de inscripción. He allí las claves del dispositivo que no puede ser jaqueado por una fuerza contraria a su propio funcionamiento político.

\begin{abstract}
The intend of this work is to carry out a reading of the myth of Prometheus in the context of the considerations expressed by F. Nietzsche and $M$. Foucault in relation to the exemplary punishment based on the characteristics of the misconduct; The transgression that it has produced is of such a magnitude that it warrants a type of punishment inscribed on the stage of the feast punitive. It is traced a certain prehistory of the art of making suffer. The work is articulated in three stages. A long paragraph referred to the myth of Prometheus. A second moment where the scene of the punishment meted out by Zeus Prometheus is analyzed. A third moment where the economy of punishment that Zeus inaugurates as a way to reassert its sovereignty, making the body torture victim in the body politic, from interbreeding with $\mathrm{M}$. Foucault considerations surrounding the punishment body- relationship is discussed.
\end{abstract}

Keywords: Myth, Punishment, Prometeus, Nietzsche, Foucault.

\section{BibLIOgRAFÍA}

DETIENNE, M. Los maestros de verdad en la Grecia Arcaica, Madrid: Taurus, 1986.
FONTENROSE, J. Work, justice, and Hesiod's five ages. In: Classical Philology, Vol. LXIX, N ${ }^{\circ} 1$, University Chicago Press, 1974, p. 1-16.

FOUCAULT, M. Vigilar y Castigar. Buenos Aires: Siglo XXI, 1976.

FOUCAULT, M. La arqueología del saber. México: Siglo XXI, México, 1984.

GERNET, L. Antropología de la Grecia Antigua. Madrid: Taurus, 1981.

NIETZSCHE, F. La Genealogía de la moral. Madrid: Alianza, 1972.

VERNANT, J.-P. Mito y pensamiento en la gracia Antigua. Barcelona: Ariel, 2001. 